\title{
Política social e controle social: estratégias de ampliação de direitos humanos
}

Social policy and social control: strategies for widening the human rights

\author{
Evelyn Secco Faquin* \\ Maria Angela Silveira Paulilo**
}

\begin{abstract}
Resumo:
O presente trabalho discute a relação existente entre os direitos sociais e o controle social, configurada pelo modelo de política social aplicado no Brasil e sua atual implementação pela esfera pública. Faz uma aproximação teórica entre direito social e cidadania e considera o controle social como um dos instrumentos viabilizadores de direitos e de políticas sociais.
\end{abstract}

Palavras-Chaves: Direitos sociais; Política social; Controle social; Esfera pública.

\begin{abstract}
:
This article discusses the existing relation between the social rights and the social control, configured by the Brazilian social policy model and its current implementation by the public sphere. It makes a theoretical approach between social rights and citizenship and considers the social control as a toll for widening rights and social policies.
\end{abstract}

Key-words: Social rights; Social policy; Social control; Public sphere.

\section{Introdução}

A discussão acerca da concepção de cidadania e sua atual configuração tem sido tema constante nos estudos contemporâneos destinados a esclarecer o que seria, de fato, esse termo, de forma a entender a amplitude atribuída a esta palavra. Podemos verificar que o termo cidadania consiste não só no poder de participação, mas, também, na apropriação de direitos.

No decorrer deste texto, discutiremos o termo cidadania, nos detendo, principalmente, na sua relação com os direitos sociais e as políticas sociais, políticas essas

\footnotetext{
* Mestre em Serviço Social e Política Social da Universidade Estadual de Londrina (UEL) e Docente do Curso de Serviço Social da Faculdade Estadual de Educação, Ciências e Letras de Paranavaí (FAFIPA). E-mail: seccofaquin@yahoo.com.br

** Docente do Departamento de Serviço Social da Universidade Estadual de Londrina (UEL), Doutora em Serviço Social pela PUC-SP. E-mail: m.angela@sercomtel.com.br
} 
que têm se tornado um dos poucos mecanismos para garantir o acesso a bens e serviços que permitem, ao cidadão, viver com dignidade. O cidadão é aquele que tem direitos garantidos e os utiliza para reivindicar sua ampliação ou sua extensão, a partir, principalmente, de estratégias relacionadas ao controle social.

Discutiremos, ainda, a dependência que os regimes democráticos têm da participação popular uma vez que ela contribui para viabilizar a concretização da cidadania e garantir a soberania popular. Apresentaremos, também, os meios de controle social, atualmente, existentes como instrumentos que podem facilitar, ou não, o exercício da cidadania.

O controle social tem sido um instrumento amplamente debatido, na área social, recurso intimamente relacionado ao exercício da participação e da cidadania. Serão discutidos seus significados e suas aplicações para que se possa entender as modificações a ele impostas e as maneiras por meio das quais se associa ao exercício da participação popular.

\section{Direitos e Cidadania: Aproximações Teóricas}

Segundo Jelin (2006), atualmente, o conceito de cidadania encontra-se ancorado na definição legal de direitos e obrigações, ou seja, restrito à idéia de que cidadania se resume na existência de um conjunto de direitos e deveres dos "cidadãos", em relação a uma sociedade que, supostamente, os contempla com estes direitos, aparentando ser algo "universal".

A autora acrescenta que a cidadania pode ser analisada a partir de duas questões, consideradas pontos chaves. A primeira dessas questões se refere à natureza dos sujeitos e o conteúdo de seus direitos; a segunda diz respeito à existência de direitos considerados universais.

Quando Jelin (2006) se propõe a discutir a primeira questão enunciada, menciona o paralelo existente entre os sujeitos individuais e os direitos coletivos, fazendo referência à tradição individualista preconizada pela ofensiva liberal e reafirmada pela ideologia neoliberal $^{1}$ nos últimos anos. Dessa maneira, fica explícita a dificuldade de se pensar no

\footnotetext{
1 "O "novo" enfoque, chamado de ajuste estrutural, pretende desencadear as "necessárias" mudanças através de políticas liberalizantes, privatizantes e de mercado. Trata-se do mesmo esquema conceitual
} 
coletivo, tendo em vista que a contemporaneidade impulsiona o individual, fazendo com que, cada vez mais, se leve em consideração as necessidades de cada indivíduo, sem refletir sobre as conseqüências que poderão surgir para o coletivo.

A outra questão enunciada por Jelin (2006) trata da existência de direitos ditos "universais" que, se assim fossem, teriam que ser acessíveis a todos os cidadãos. A autora nos chama, ainda, a atenção para a necessidade do respeito ao pluralismo, ou seja, não se deve pressupor o que determinada parcela da população precisa, sem considerar o histórico de sua constituição, sua identidade e seu papel na sociedade atual.

Uma reflexão que se faz necessária, é a apresentada por Couto (2004), que afirma que os direitos sociais são fundamentados pela idéia de igualdade e possuem caráter distributivo, tendo assim, como fundamento central, as necessidades reais do homem.

A autora ainda acrescenta que sua definição é de um produto social histórico e, portanto, inacabado, trazendo na sua configuração matizes das populações no enfrentamento das contradições geradas pelo capitalismo.

Assim, verificamos que a discussão acerca do que, de fato, seria a cidadania não pode reduzir-se a direitos e deveres, sendo de extrema importância analisar todas as faces desta questão.

Uma constante se mantém acerca do tema cidadania, ela está intrinsecamente vinculada aos direitos existentes e àqueles que ainda estão por vir, principalmente, os direitos sociais.

Referimo-nos a direitos existentes e inexistentes, pois estamos imersos em um processo histórico que se metamorfoseia a todo instante. Tudo que faz parte deste processo tende a sofrer constantes mudanças. Os direitos, por sua vez, não podem ser excluídos dessa dialética.

Devido a este processo dialético, esses direitos são definidos, ou, como afirma Bobbio (1992), os direitos não são colocados todos de uma vez nem de uma vez por todas, seu aparecimento ou desaparecimento têm sido determinados pela malha social.

denominado em alguns países neoliberalismo, também identificado como liberalizante-privatizante. A proposta se resume, para o chamado curto prazo, em diminuir o déficit fiscal reduzindo o gasto público; aplicar uma política monetária restritiva para combater a inflação e fazer prevalecer uma taxa de juros "real positiva" e um tipo de câmbio "real adequado". A médio prazo os objetivos seriam transformar as exportações no motor de crescimento; liberalizar o comércio exterior; atenuar as regulações estatais atribuindo o papel de regulador ao mercado; concentrar o investimento no setor privado, reduzindo a presença do setor estatal; e promover uma estrutura de preços sem distorções" (SOARES, 2001, p. 18). 
Bobbio (1992) ainda assevera que os direitos constituem uma classe variável, mutável com o passar dos anos, o que impede uma definição permanente dos direitos do homem, uma vez que são modificados de acordo com as mudanças sociais.

A concepção de cidadania se torna, desta forma, igualmente mutante, à medida que, assim como os direitos, está em constante movimento.

Outro ponto ressaltado por Bobbio (1992) e referendado por Bussinger (1997), é a distância existente entre os direitos existentes e sua verdadeira aplicação. Em outras palavras contamos, atualmente, nesse campo, com um grande arcabouço legal. Sua aplicação, no entanto, faz-se cada vez mais difícil. Embora existam leis para garanti-los, sua efetivação pode vir a ser nula ou ineficaz.

\begin{abstract}
Quando se trata de enunciá-los, o acordo é obtido com relativa facilidade, independentemente do maior ou menor poder de convicção de seu fundamento absoluto; quando se trata de passar à ação, ainda que o fundamento seja inquestionável, começam as reservas e as oposições. O problema fundamental em relação aos direitos do homem, hoje, não é tanto o de justificá-los, mas o de protegê-los. Trata-se de um problema não filosófico, mas político (BOBBIO, 1992, p. 24).
\end{abstract}

Estes autores reiteram que nosso grande desafio, no momento, não é a criação de novos direitos, mas sim, impulsionar a luta para a garantia dos direitos, agora, existentes, sendo até mesmo necessária a expansão de alguns deles, em função do surgimento de novos tipos de discriminação ou de exacerbação de preconceitos já existentes anteriormente. A condição de vulnerabilidade ${ }^{2}$, que afeta estes novos discriminados, como é o caso, por exemplo, de pessoas portadoras de HIV, ou o recrudescimento da xenofobia, em vários países, faz com que determinados direitos sejam extensíveis, para que um tratamento igualitário seja garantido por sua específica ampliação a estes segmentos estigmatizados.

Bobbio (1992) parafraseia Arendt que afirma ser o grande direito, o direito a ter direitos. Assim, mediante este universo em movimento, são várias as estratégias a serem implementadas para se conseguir a garantia desses direitos e para que se alcançar um modelo de cidadania.

\footnotetext{
2 “Castel (2003) explica que a vulnerabilidade se caracteriza por uma condição de miséria vivenciada e de dissociação social. Essa condição de estar parece ter um efeito cumulativo na fragilização das relações familiares e nas relações mais amplas" (MARCELINO, 2006, p. 80).
} 
As políticas sociais, por sua vez, constituem-se em estratégias de garantias de direitos ao mesmo tempo em que são, igualmente, necessárias para a manutenção da lógica do capital. Dessa forma, as políticas sociais e os bens e serviços por elas implementados acabam sendo essenciais, tanto para a população, quanto para o próprio Estado.

\begin{abstract}
Portanto, se tais serviços, de um lado, favorecem os trabalhadores, como resultante de suas próprias conquistas no sentido de suprir necessidades básicas de sobrevivência nessa sociedade, por outro lado, sua implementação, ao ser mediatizada e gerida pela classe capitalista, passa a se constituir em um dos instrumentos políticos de reforço do seu poder, face ao conjunto da sociedade (IAMAMOTO; CARVALHO, 2005, p. 93).
\end{abstract}

Em sendo assim, a política social apresenta elementos conflitantes, pois, à medida que é uma estratégia do Estado para assegurar a exploração de seus subalternos, ela também se torna um dos meios de materialização de direitos, na maioria das vezes, conquistados pela mobilização de seus usuários, pois grande parte deles deve sua ampliação a lutas populares.

De acordo com Zwiedneck (apud Santos, 1998) a política social, em si, é o conjunto de todas as medidas destinadas a atenuar os antagonismos de classe. Figueiredo (1997) também compartilha dessa concepção e define, como política social, o conjunto de atividades ou de programas destinados a remediar falhas do mercado, ou melhor, tem a função de minimizar as conseqüências da exploração intrínseca ao sistema capitalista.

Santos (1998) concebe a implementação de políticas sociais específicas, como escolhas trágicas, dado ao seu caráter seletivo e, sendo assim, excludente.

\footnotetext{
A inexistência de uma definição precisa de política social explica-se por seu caráter de metapolítica, matriz de princípios ordenadores de escolhas trágicas, embutidas estas em praticamente todas as políticas específicas (SANTOS, 1998, p. 51).
}

O autor usa a expressão escolha trágica, pois pressupõe, nos seus critérios de aplicação, a classificação e a mensuração. As políticas sociais, na maioria das vezes, têm caráter seletivo, buscando a adoção de critérios para sua operacionalização, que acaba levando ao beneficiamento de alguns em detrimento de outros, devido à escassez de recursos, ou mesmo, ao descaso com o social, devido à prevalência da política econômica 
sobre a política social. Kliksberg (2002, p. 35-36) reforça essa afirmativa, quando diz que "a experiência das últimas décadas indica que, diante da tradicional desarticulação entre o econômico e o social, como muitas vezes já se disse, as políticas sociais estão dedicadas, na verdade, a 'recolher os mortos e feridos que a política econômica vem deixando'".

Behring e Boschetti (2006) nos chamam atenção para a dualidade discriminatória, gerada pela privatização emergente de serviços ou de bens sociais, desde a década de 1990, entre aqueles que podem e aqueles que não podem pagar por eles, como tem, visivelmente, acontecido com a saúde e com a educação.

Quando nos detemos na realidade brasileira, verificamos que esta diferenciação fica ainda mais gritante, pois, embora o país tenha uma Constituição que mencione um invejável conjunto de direitos sociais, sua garantia, com o passar dos anos, fica cada vez mais prejudicada, gerando um sentimento de desesperança social. Antunes (2005, p. 03), em um de seus artigos expressa muito bem esse fato.

\footnotetext{
Por que tal fenômeno se efetivou? Por que, em vez do início da descontinuidade e ruptura com o neoliberalismo, o Governo Lula postou-se como expressão forte de sua continuidade? As explicações são, por certo, complexas, mas se encontram em grande medida na contextualidade vivenciada na década de 1990, que venho já há algum tempo denominando a década da desertificação social e política neoliberal. [...] A partir de 1990, com a ascensão de Collor e depois FHC, esse processo intensificou-se sobremaneira, com a implementação de inúmeros elementos que reproduzem, nos seus traços essenciais, o receituário neoliberal e o seu processo de reestruturação produtiva (ANTUNES, 2005, p. 95).
}

Behring e Boschetti (2006) lembram um outro aspecto relevante que consiste nos princípios promulgados no artigo 194 do Capítulo II (Da Seguridade Social) do Título VIII (Da Ordem Social) da Constituição, que deveriam orientar a operacionalização da seguridade social no Brasil: universalidade, uniformidade e a equivalência; seletividade e a distributividade; irredutibilidade, diversidade, caráter democrático e descentralizado. No entanto, de fato, estes princípios nunca foram considerados como base do sistema de proteção social brasileiro.

O Brasil jamais possuiu um sistema de proteção social consolidado, surgindo suas primeiras iniciativas somente no governo do então presidente Getúlio Vargas, na década de 1930. Cabe mencionar que foi, também nesta década, que as mulheres adquiriram seu direito ao voto e somente com a Constituição Federal de 1988 o sufrágio se tornou 
universal no país. Desde então, a ampliação desde sistema se deu a partir de mobilizações e lutas das classes populares. Esta realidade não é restrita ao Brasil, Jelin (2006) ressalta o histórico de concretização dos direitos humanos na América Latina, marcado por uma série de lutas políticas e ideológicas. A autora acrescenta ainda que, durante todo o século XX, a predominância dos regimes populistas e do autoritarismo, na América Latina, produziu uma cultura em que a consciência dos direitos do cidadão passou a ser limitada. Deste modo, a expansão que se pode notar dos direitos trabalhistas e sociais na região, em conseqüência das políticas sociais, nem sempre tem sido resultado de implantação integral dos direitos civis e políticos.

Esse contexto, agravado com a ofensiva neoliberal, direcionada à área social, tende a apresentar ainda mais rachaduras. Soares (2001) nos mostra que onde já havia um sistema de proteção social consolidado, ou seja, um Estado de Bem-Estar Social montado, profissionalizado e com recursos abundantes de financiamentos, as políticas de ajuste estrutural sofreram resistências concretas, tanto da burocracia de Estado, quanto das populações-alvo. No entanto, completa Soares (2001), para os países onde não existia este sistema de proteção, formado por políticas sociais de caráter universal, os impactos das políticas de ajuste sobre a pobreza e a desigualdade social vieram, em sua maioria, afetar os mecanismos econômicos e sociais. Cita, como exemplos, a abertura comercial, a deslocalização de indústrias e o desemprego.

Tendo em vista a realidade brasileira, acrescenta Soares (2001), o problema tornouse dramático nos últimos anos, tanto do ponto de vista econômico, quanto social. Do ponto de vista econômico, reforça Soares (2001), apesar de ter sido o Brasil, o país sulamericano a mostrar maior resistência às políticas de desregulamentação financeira e de abertura comercial irrestrita, sendo o último país a ceder ao neoliberalismo, todos os impactos das políticas de ajuste estão se sobrepondo com grande intensidade e em um curto espaço de tempo. Do ponto de vista social, continua Soares (2001), o país foi pego a meio caminho na sua tentativa de montagem de um Estado de Bem-Estar Social.

Este breve ensaio de construção do Estado de Bem-Estar Social brasileiro, afirmam Behring e Boschetti (2006), consistiu em uma reforma, uma tentativa temporal e geopoliticamente situada de combinar acumulação e diminuição dos níveis de desigualdade, com alguma redistribuição de renda. 
No entanto, relata Soares (2001), dada à grande pobreza estrutural presente no Brasil, cuja população é, em sua maioria, praticamente excluída dos benefícios do desenvolvimento passado, o país é atingido pelos dois lados, o desenvolvimento e o subdesenvolvimento. Vale dizer, sofre todos os percalços das políticas de ajuste comuns aos países desenvolvidos e subdesenvolvidos.

Behring e Boschetti (2006) acrescentam que o ideário neoliberal preconizava que a reforma do Estado, com ênfase especial nas privatizações e na previdência social e, acima de tudo, o desprezo às conquistas de 1988 no terreno da seguridade social e outros - a carta constitucional era vista como perdulária e atrasada -, abriria o caminho para o novo "projeto de modernidade". Dessa maneira poderia se atingir o tão "sonhado" desenvolvimento, acabando, assim, com os problemas estruturais brasileiros.

As autoras ainda mencionam a estratégia da publicização das atribuições protetivas do Estado, nas quais se pode perceber a responsabilização da família e da sociedade civil para a execução da seguridade social, sendo uma das iniciativas marcantes, neste aspecto, o estabelecimento de parcerias com Organizações não Governamentais e Instituições Filantrópicas para a implementação das políticas. A essa nova arquitetura institucional na área social - sempre ignorando o conceito constitucional de seguridade se combinou o serviço voluntário, que desprofissionaliza a intervenção nessas áreas, remetendo-a ao mundo da solidariedade, da realização do "bem comum" pelos indivíduos, por meio de um trabalho voluntário não-remunerado, minando assim, o conceito de política social, retornando à benemerência, ou mesmo, à caridade.

Mediante este contexto conflituoso, parece complicado pensar nas políticas sociais como meio de viabilização de direitos, ou mesmo, constituição de um modelo de cidadania. No entanto, o exercício do controle social em relação às políticas, juntamente com a pressão popular, já conhecida pelos brasileiros, continuam meios para buscar mudanças nessa realidade.

\section{O controle Social como Viabilizador de Direitos e Políticas Sociais}

Conforme Teixeira (2001), os direitos são a base para a formação de uma sociedade civil autônoma, mas direitos são abstratos e necessitam de ações da sociedade para sua concretização. Uma destas ações está diretamente associada ao controle social. 
Sua efetivação, contudo, em muitos países, depende da própria sociedade civil, da cultura política e de sua organização, que também deverá zelar pela construção de novos direitos de acordo com novas necessidades e aspirações (TEIXEIRA, 2001, p. 45).

De acordo com Bravo (2006), historicamente, a categoria controle social foi entendida apenas como controle do Estado ou do empresariado sobre as massas. Sendo assim, esse é o entendimento quase sempre presente na sociologia clássica quando trata do controle social, expressando dessa maneira, um caráter coercitivo, repressor.

No entanto, quando analisamos o termo, à luz da Constituição Federal de 1988, verificamos, segundo Bravo (2006), que ele expressa a participação da população no sentido de elaborar, implementar e fiscalizar as políticas sociais. Vê-se, assim, que o conceito de controle social pode ser compreendido a partir de duas perspectivas. A primeira concebe o controle social como uma forma de exercício do controle do Estado em relação à sociedade, principalmente, por meio de suas instituições. A segunda entende o controle social como forma de controle da sociedade sobre o Estado, por meio da fiscalização e participação nas decisões referentes à coisa pública.

Wendhausen (2002) aprofunda uma discussão iniciada por Cohen, em relação ao termo controle social, inferindo que ele deveria ser chamado de controle público. A justificativa para esta denominação parte da constatação de que a correlação de forças que existe no país provoca, de fato, uma forma de controle social na sua concepção conservadora. Neste sentido, o controle social encontra-se instalado, por meio de uma forte concentração de poder de caráter conservador, pela maioria dos governos, nos níveis federal, estadual e municipal. A autora considera que, ao incentivar o "controle público", as questões relacionadas às políticas sociais deveriam sofrer uma maior interferência da sociedade civil, ou seja, o controle governamental deveria ser menor e o controle público maior, mesmo quando se trata de governos estaduais e municipais referidos como "progressistas" ou "populares".

Behring e Boschetti (2006) relatam que a concepção de controle democrático, também conhecida como controle social, na Constituição de 1988 e no início da experiência dos conselhos de políticas públicas e de defesa de direitos no Brasil, foi uma grande inovação política e institucional. Estas instâncias se fizeram sentir no formato das 
políticas públicas brasileiras, nas quais se vislumbrava uma perspectiva nítida de reforma, num país em que a democracia sempre foi mais exceção do que regra.

A Constituição de 1988, em seu texto, nos traz uma perspectiva de participação que, de acordo com Behring e Boschetti (2006), promove a transparência na deliberação das ações, democratiza o sistema decisório; permite maior expressão e visibilidade das demandas sociais e, por último, a sociedade adquire espaços garantidos por lei para sua manifestação, alcançando as esferas estatais e a possibilidade de alargar seus direitos e defendê-los.

Os Conselhos, acrescentam Behring e Boschetti (2006), têm grandes potencialidades como arenas de negociação de propostas e ações. No entanto, há também dificuldades para a realização dos mecanismos da participação e cumprimento de seu papel de modo efetivo e eficaz. "Foi exatamente para aperfeiçoar o processo democrático, restrito à democracia representativa, que foram criadas instâncias estratégicas como os conselhos: arenas de discussão das demandas e interesses presentes em áreas determinadas" (BEHRING; BOSCHETTI, 2006, p. 179).

A concretização do controle social, como instrumento de fiscalização e participação, conta com alguns mecanismos como: audiências públicas; iniciativas populares como plebiscito e referendo; petições e reclamações; conselhos municipais, estaduais e federais; e fiscalização de órgãos públicos. As manifestações por parte da população têm sido, no entanto, restritas às lideranças locais e as reivindicações têm se limitado, em sua maioria, ao coletivo de uma comunidade ou um território. Não se pode negar serem estas manifestações um avanço, se nossa referência partir da grande dispersão de pessoas como indivíduos isolados, mesmo quando se encontram em uma situação de vivências semelhantes ou de proximidade física.

Raichelis (2005) considera o controle social peça chave na constituição do espaço público. Concebe, como componentes da esfera pública, a visibilidade, o controle social, a representação de interesses coletivos, a democratização e, por fim, a cultura pública. Segundo Garcia (2007), quando passamos a discutir a concepção de esfera pública, podemos verificar que se trata, de um espaço no qual se implementam relações discursivas orientadas para o entendimento no enfrentamento dos conflitos diversos que 
surgem das contradições sociais. É uma rede que não se organiza de forma isolada, ocorre em todos os lugares, é movimento.

\begin{abstract}
A esfera pública não pode ser entendida como uma instituição, nem como uma organização, pois ela não constitui uma estrutura normativa capaz de diferenciar entre competências e papéis, nem regula o modo de pertença a uma organização, etc. Tampouco ela constitui um sistema, pois, mesmo que seja possível delinear seus limites internos, exteriormente ela se caracteriza através de horizontes abertos, permeáveis e deslocáveis. A esfera pública pode ser descrita como uma rede adequada para a comunicação de conteúdos, tomada de posição e opiniões; nela os fluxos comunicacionais são filtrados e sintetizados, a ponto de se condensarem em opiniões públicas enfeixadas em temas específicos (HABERMAS apud GARCIA, 2007, p. 04).
\end{abstract}

Assim, Teixeira (2001) vem reforçar o conceito de esfera pública, como sendo formada por estruturas mistas, nas quais se verifica a presença da sociedade civil, mas de modo vinculado ao Estado, por sua criação, composição e manutenção de estruturas comunicacionais generalizadas como, por exemplo, a mídia.

No entanto, algo imprescindível de ser citado, é que a sociedade civil não é homogênea, mas atravessada pelos interesses e tensões que fazem parte de uma sociedade cindida, de classes e frações de classes, além de outras contradições articuladas e/ou decorrentes desta. Portanto, não se pode ter uma visão romântica de que todos os representantes da sociedade civil defendem os mesmos princípios e o interesse público. Há, assim, a necessidade, de se reconhecer e fortalecer outros mecanismos de controle: ministério público, imprensa, conselhos de fiscalização das profissões e outros; não se esquecendo de priorizar o fortalecimento dos movimentos sociais.

Cabe, ainda, dizer que o controle social aparece inseparavelmente ligado à participação. Segundo Nogueira (2004), no mundo da sociedade de classes, do capitalismo e do Estado democrático representativo coexistem e se combinam, de diferentes maneiras, quatro modalidades de participação: a participação assistencialista, a participação coorporativa, a participação eleitoral e a participação política.

A participação assistencialista apresenta uma natureza filantrópica ou solidária e tem sido uma atividade universal, pertencente a todas as épocas. Aparece, de forma muito evidente nos segmentos sociais pauperizados e marginalizados, como estratégia de 
sobrevivência e consiste em práticas de auxílio mútuo e de mutirão associadas, na maioria das vezes, a uma ação de cunho religioso ou filantrópico.

A participação corporativa está associada à defesa de interesses de determinados grupos sociais ou de categorias profissionais. Trata-se de uma participação voltada para objetivos particulares dos membros pertencentes aos grupos ou categorias profissionais. Como a anterior, esta é também uma modalidade universal de participação e teve especial importância na origem do sindicalismo moderno.

A participação eleitoral associa-se ao campo político, propriamente dito. Não defende apenas interesses particulares, mas interfere na governabilidade e seus efeitos se fazem sentir em toda a coletividade. Este tipo de participação, embora de caráter mais político, tem seus limites como seu condicionamento a atos e escolhas individuais e não leva, necessariamente, a uma reorganização sustentada do Estado ou do poder político. $\mathrm{O}$ voto é, ainda, um veículo de expressão muito restrito que reduz o envolvimento do cidadão. Não deixa de ser, contudo, uma forma política de participação e uma ação em defesa de determinados interesses.

A participação política não exclui as duas modalidades, logo acima mencionadas, embora as complemente e as supere. A participação política visa à comunidade como um todo, a organização da vida social em seu conjunto, ou seja, o Estado. Diz respeito a questões caras a um projeto democrático, tais como, a questão do poder, da dominação, do consenso, da hegemonia, a partir da força ou do convencimento. É esta modalidade de participação que consolida, protege e dinamiza a cidadania e todos os variados direitos humanos e, justamente por isso, têm nos cidadãos, seus protagonistas centrais (NOGUEIRA, 2004, p. 130 - 133).

Nogueira (2004) admite, ainda, que, nos dias de hoje, principalmente após a Constituição Federal de 1988, a participação se dá de maneira valiosa e afirma que tem havido alguns avanços. No entanto, não a concebe como exemplo de manifestação popular ou de garantia de direitos, uma vez que pode ser facilmente manipulada e utilizada a favor das elites, tornando-se, assim, um grande entrave à integridade do processo participativo.

Mesmo utilizada, por parte dos governantes, como instrumento mantenedor da hegemonia, por parte dos governados constitui-se um importante meio de se fazer ouvir 
e de se fazer representar por representantes autênticos que defendam os interesses daqueles que os elegeram. Segundo Nogueira (1998, p. 221), nosso sistema de representação política - alicerce do que seria uma democracia auto-sustentada - esteve sempre submetido a uma espécie de desestruturação que o atrofiou e em certo sentido infantilizou.

Ainda segundo o autor, quando a participação é ampliada, condiciona os governos e a administração pública. Esboça um entendimento do que seria uma gestão participativa e sugere alguns elementos centrais: a busca da modificação da articulação entre governantes e governados; a introdução de novas formas de controle social, entendido, aqui, como controle do governo pela sociedade; a forma de ação descentralizada e o fomento de parcerias, dentro e fora do Estado sem diminuir a intervenção estatal; a busca de iniciativa e criatividade de forma a alcançar resultados efetivos, abertos à transformação social; a exigência de alterações significativas na forma de gerenciar e organizar recursos e procedimentos, o que conduz a uma "reforma administrativa"; orientar-se por critérios de "flexibilidade", eficiência e agilidade; assumir a forma de planejamento estratégico, democrático e dinâmico, ao invés de continuar com o tradicional planejamento normativo e tecnocrático; compreender que somente a participação não é suficiente para provocar avanços, mas depende, igualmente, de profissionais qualificados que dominem o campo técnico-científico, que sejam capazes de pensar de modo complexo, que realizem análises concretas de situações concretas e que imprimam outro padrão ético à administração (NOGUEIRA, 2004, p. 145-151).

Vê-se, portanto, que a participação somente se viabiliza, quando integrada a mecanismos de representação e torna-se mais efetiva quando interfere diretamente na formulação e implementação de política. Nas palavras de Nogueira (2004) a participação é uma construção política.

As questões da participação e do controle social assumiram tal relevância, para os profissionais que atuam na área da política de assistência social, através de seus Conselhos e demais instâncias de discussão e decisão, que fizeram com que fossem estes os temas do processo de conferências de assistência social que envolveu municípios e Estados e culminou na VII Conferência Nacional de Assistência Social. 
Dessa maneira, tanto a participação deve ser garantida constitucionalmente, como a população deve ser capaz da apropriação deste espaço, de maneira a pressionar o Estado para o fortalecimento de seus mecanismos de controle sobre ele. Assim a população, ao se manifestar, ocupará o espaço que the é de direito na gestão dos assuntos que lhe dizem respeito, cabendo aos cidadãos, detentores de direitos, o desafio de transformar essa intenção em ação.

\section{Considerações Finais}

Há que se reconhecer grandes limites para a efetivação do controle social no país. A herança assistencialista das políticas sociais, em especial, a Política de Assistência Social, os limites institucionais que tolhem iniciativas mesmo em seu início, a própria experiência do exercício de democracia no país são obstáculos a serem ainda vencidos.A inexistência de um regime democrático, na maior parte da história brasileira, alicerçou instituições cerceadoras do exercício da cidadania e reforçou hábitos culturais voltados a não participação dificultando, ainda mais, a construção de experiências e a efetivação de processos democráticos, ou seja, momentos e situações em que a população pudesse se reconhecer como sujeito de direitos.

Este cenário favorece posições e ações de pouca eficácia e fragmentadas quando se trata do enfrentamento das expressões da questão social. Leve-se, ainda, em consideração políticas sociais abertamente utilizadas como mecanismos de acomodação em momentos de crise e de alívio das tensões sociais. Em sendo assim, perpetua-se a manutenção e a regulação da ordem social, por meio de uma cultura de participação popular tangencial e periférica. Em decorrência do constante reforço a este estilo de participação, a população, nos dias de hoje, custa a acreditar que seja capaz de controlar uma política social quando demandas cotidianas e imediatas como alimentação, moradia, emprego se afiguram tão distantes de seu poder de decisão.

Pode-se concluir que, por mais que as formas de participação sejam limitadas, ela é entendida, dentre seus atores, como um dos meios eficazes de democratização ou redemocratização. Quando o Estado não atende, suficientemente, às carências da população, ela encontra, na mobilização e na organização, suas armas para a concretização de seus direitos. Através da articulação de grupos e de sujeitos que vivem 
dificuldades e carências semelhantes pode se iniciar um movimento em busca da concretização de atendimento, da minimização ou da supressão destas carências, pressões próprias de um regime democrático.

Faz-se, portanto, fundamentalmente necessário, para a consolidação de um regime democrático, um aumento progressivo e cada vez mais impactante das diversas formas existentes de participação popular. Faz-se igualmente necessário propiciar à população como um todo, o acesso a informações referentes a esses mecanismos. Fortalece-se assim, o embate contra a ofensiva neoliberal e a efetivação dos direitos promulgados, mas não, ainda, garantidos.

\section{Referências}

ANTUNES, R. A Desertificação Neoliberal no Brasil. Campinas: Autores Associados, 2005.

BEHRING, E. R.; BOSCHETTI, I. Política Social: Fundamentos e História. São Paulo: Cortez, 2006.

BOBBIO, N. A Era dos Direitos. Rio de Janeiro: Campus, 1992.

BRAVO, M. I. S. Desafios atuais do controle social no Sistema Único de Saúde (SUS). Serviço Social \& Sociedade. São Paulo: Cortez, no 88, nov., 2006, p. 75-100.

BUSSINGER, V. V. Fundamentos dos direitos humanos. Serviço Social \& Sociedade. São Paulo: Cortez, no 53, mar., 1997, p. 09-45.

BRASIL. Constituição da República Federativa do Brasil. Brasília: Senado Federal, 1988.

COUTO, B. R. O Direito Social e a Assistência Social na Sociedade Brasileira: uma equação possível? São Paulo: Cortez, 2004.

GARCIA, B. Z. Democracia Deliberativa, Esfera Pública e Políticas Sociais. 2007. mimeo.

FIGUEIREDO, A. C. Princípios de justiça e avaliação de políticas. Revista Lua Nova. São Paulo: CEDEC, no 39, 1997, p. 73-103.

IAMAMOTO, M.; CARVALHO, R. Relações Sociais e Serviço Social no Brasil. 18 ed. São Paulo: Cortez, 2005.

JELIN, E. Cidadania revisitada: Solidariedade, Responsabilidade e Direitos. In: JELIN, E.; HERSHBERG, E. (Orgs.). Construindo a democracia: direitos humanos, cidadania e Sociedade na América Latina. São Paulo: Edusp, 2006. 
KLIKSBERG, B. Repensando o Estado para o Desenvolvimento Social: superando dogmas e convencionalismos. 2 ed. São Paulo: Cortez, 2002.

MARCELINO, E. J. Adolescentes em Londrina: histórias de vida e histórias de rua. Dissertação (Mestrado em Serviço Social e Política Social), 2006, Universidade Estadual de Londrina, Londrina.

NOGUEIRA, M. A. Um Estado para a sociedade civil: temas éticos e políticos da gestão democrática. São Paulo: Cortez, 2004, p. 130 - 133.

RAICHELIS, R. Esfera pública e conselhos de assistência social: caminhos da construção democrática. 3 ed. São Paulo: Cortez, 2005.

SANTOS, W. G. A trágica condição da política social. In: ABRANCHES, S. H.; SANTOS, W. G.; COIMBRA, M. A. (Orgs.). Política Social e Combate à Pobreza. Rio de Janeiro: Jorge Zahar, 1998.

SOARES, L. T. R. Ajuste Neoliberal e Desajuste Social na América Latina. Petrópolis: Vozes, 2001.

TEIXEIRA, E. O local e o global. São Paulo: Cortez, 2001.

WENDHAUSEN, A. O duplo sentido do controle social. Itajaí: Univali, 2002. 